\title{
Ensino de Paleontologia: uma abordagem não-formal no Laboratório de Paleontologia da Universidade Federal de Sergipe
}

\author{
Leonardo Ferreira de Almeida \\ Departamento de Biologia da Universidade Federal de Sergipe. \\ leobioufs@hotmail.com \\ Maria Helena Zucon \\ Departamento de Biologia da Universidade Federal de Sergipe. \\ Zucon_1@ hotmail.com \\ Jobeane França de Souza \\ Departamento de Biologia da Universidade Federal de Sergipe. \\ jobeane@hotmail.com \\ Vinícius Silva Reis \\ Departamento de Biologia da Universidade Federal de Sergipe. \\ vinicius_bioufs@yahoo.com.br \\ Fabiana Silva Vieira \\ Departamento de Biologia da Universidade Federal de Sergipe. \\ fabiannavieira@yahoo.com.br
}

\begin{abstract}
PALEONTOLOGY TEACHING: A NON-FORMAL APPROACH. This study aimed to evaluate the contribution of the Laboratory of Paleontology at the Universidade Federal de Sergipe as an area of non-formal educational disseminaton of knowledge of paleontology to students of the $7^{\text {th }}$ grade from municipal public schools in Aracaju. The students had access to the collection of Sergipe fossils, through visits to the exhibition, where concepts, importance and applications of fossils were discussed. It was analyzed 164 texts written by the students, which presented subjective evaluations about the visitation. Interviews carried out with the responsible teachers were analyzed, thus showing their ideas about the contribution of the discussed knowledge to the process of teaching and learning of their students. Through qualitative analysis of texts and interviews, it was concluded that the exhibition, as an area of non-formal education, can promote a dissemination of knowledge about Paleontology, allowing a stimulating and interactive learning process. Citation: Almeida L.F.de., Zucon M.H., Souza J.F.de., Reis V.S., Vieira F.S. 2014. Ensino de Paleontologia: uma abordagem não-formal no Laboratório de Paleontologia da Universidade Federal de Sergipe. Terræ Didatica, 10(1):14-21. <http://www.ige.unicamp.br/terraedidatica/> .
\end{abstract}

KEY WORDS: Fossils; Science Teaching, Education practices.

RESUMO - O presente estudo objetivou avaliar a contribuição do Laboratório de Paleontologia da Universidade Federal de Sergipe como espaço de educação não-formal, assim como reconhecer este espaço como disseminador de conhecimentos sobre Paleontologia para alunos do $7^{\circ}$ ano das escolas públicas municipais de Aracaju. Os alunos tiveram acesso ao acervo fossilifero, através de visitas à exposição, onde foram discutidos conceitos, importância e aplicações do uso dos fósseis como instrumento para a reconstrução de eventos e ambientes pretéritos. Foram analisados 164 textos confeccionados pelos discentes contendo avaliações subjetivas sobre o processo de visitação. Foram analisadas entrevistas, desenvolvidas junto aos professores responsáveis por cada classe, permitindo avaliar as concepções dos docentes sobre a contribuição da visita no processo de ensino-aprendizagem dos seus alunos. Por intermédio da análise qualitativa dos textos e das entrevistas, conclui-se que a exposição, enquanto espaço de educação não-formal, é capaz de difundir os conhecimentos paleontológicos permitindo aprendizado lúdico e interativo.

PALAVRAS-CHAVE: Fósseis, Ensino de Ciências, Práticas educativas 


\section{Introdução}

A escola tem papel fundamental na abordagem dos conhecimentos científicos, no entanto, devido ao direcionamento do ensino voltado para o vestibular, cada vez mais cedo nas séries escolares, muitos assuntos são pouco trabalhados ou algumas vezes chegam a ser negligenciados. Como consequência, a atenção dos professores é voltada para os temas que são amplamente explorados nas provas de vestibular. Desta forma, outros conteúdos, como exemplo a Paleontologia, não são devidamente abordados (Vieira et al. 2010). Além disso, o emprego de uma linguagem muito técnica e distante das experiências particulares dos alunos, associado às deficiências dos livros didáticos, contribui para uma abordagem ineficaz de determinados conteúdos escolares.

Uma forma de resolver este impasse é a implementação de ações educativas em espaços extraescolares, contribuindo para que os saberes produzidos fora da sala de aula se tornem acessíveis para a comunidade estudantil (Krasilchk e Marandino 2004). Hoje, vários espaços contribuem para o mesmo fim educativo tendo como meta suprir a sociedade em suas carências de conhecimento, possibilitando o empoderamento cultural e científico (Valente et al. 2005).

Projetos de divulgação científica estimulam a ampliação dos espaços não-formais de ensino de ciências, sendo que instituições extraescolares como museus e universidades são seus exemplos mais representativos. Desta forma, a educação não-formal surge e se consolida como uma via eficaz entre ensino, pesquisa e extensão, estreitando relações com o ensino formal (Schwank e Silva 2004). Sendo assim, a educação científica não seria prática exclusiva das escolas.

De acordo com Moreira (2006), o conhecimento que o público tem sobre os temas científicos mais atuais e relevantes vem da divulgação por meio de mídia eletrônica de qualidade, criação de centros e museus de ciência, revistas e websites; maior cobertura de jornais sobre temas de ciência e publicação crescente de livros; organização de conferências populares e outros eventos que despertam interesse em audiências diversificadas por todo o país.

Por educação formal, entende-se a educação sistematizada pelas escolas enquanto que a educação informal abrange todas as possibilidades educativas no decurso da vida do indivíduo, constituindo um processo permanente e não organizado (Afonso
2001). Por último, a educação não-formal, a qual obedece a uma estrutura e a uma organização distinta das escolas, diverge ainda da educação formal no que respeita a não fixação de tempos e locais e também à flexibilidade na adaptação dos conteúdos para cada grupo.

Vale ressaltar que muitos conteúdos não estão presentes no currículo obrigatório do ensino formal, sendo tratados como temas transversais que apresentam natureza diferente dos assuntos convencionalmente abordados nas escolas, visto que discutem experiências vividas pela sociedade e pelas comunidades em seu cotidiano. Desta forma, estes temas podem ser tratados de maneira não-formal em diversos espaços sócio-culturais (Brasil 1998).

Conforme Valente e colaboradores (2005), muitas vezes os temas transversais não são conduzidos de maneira satisfatória na sala de aula, devido à discrepância entre a linguagem científica e a linguagem do cotidiano. Segundo Schwanke e Silva (2004), este é o caso da Paleontologia, que apesar de estar relacionada aos conteúdos de Biologia, Geografia e História, caracteriza-se como uma ciência que enfrenta dificuldades em se inserir como conteúdo programático na ementa escolar.

Devido a este fato, o ensino não-formal promovido por instituições de pesquisa e de ensino superior, apresenta-se como principal via de disseminação dos conhecimentos sobre Paleontologia. Tal difusão se dá, principalmente, através de projetos de extensão que são direcionados tanto para a comunidade acadêmica quanto para os estudantes de escolas públicas e particulares. As exposições de coleções de fósseis, presentes em museus, casas de ciência e universidades são recursos fundamentais para inserir os conteúdos sobre Paleontologia na Educação Básica (Schwanke e Silva 2004).

O Laboratório de Paleontologia, parte integrante do Departamento de Biologia da Universidade Federal de Sergipe, constitui-se num destes espaços não-formais de ensino, possuindo um acervo composto por quase 6.000 fósseis catalogados. A este, encontra-se anexada uma exposição permanente e de livre acesso para as escolas.

$\mathrm{Na}$ exposição, encontram-se os exemplares mais representativos deste acervo, os quais permitem tanto difundir informações básicas sobre Paleontologia, quanto evidenciar o conhecimento do ambiente pretérito de Sergipe, além de possibilitar o entendimento sobre a origem e evolução do Oceano Atlântico. O laboratório recebe alunos da própria instituição e de escolas públicas e particulares 
do Estado, assumindo um importante papel como propagador dos conhecimentos paleontológicos.

No intuito de avaliar a contribuição e importância do Laboratório de Paleontologia como agente disseminador dos conhecimentos paleontológicos de Sergipe para estudantes do ensino básico, foi realizado um trabalho com os estudantes do Ensino Fundamental da Rede Pública Municipal de Aracaju, Sergipe. Para atingir tal objetivo geral, foram adotados os seguintes objetivos específicos:

i) possibilitar aos estudantes o acesso ao acervo de fósseis, através de visitas à exposição;

ii) avaliar o aprendizado dos alunos sobre conceitos básicos em Paleontologia resultantes dessa experiência;

iii) analisar as concepções dos professores sobre como o processo de visitação pode ter contribuído para a aprendizagem dos alunos.

\section{Ensino Não-Formal de Paleontologia}

O objeto de estudo da Paleontologia são os fósseis, que compreendem qualquer evidência, direta ou indireta de vida, com mais de 11.000 anos e incluem desde restos resistentes dos próprios organismos até vestígios ou marcas indicativas de atividades biológicas. Muitos seres encontrados atualmente têm representantes no registro fossilífero, demonstrando assim que nem todo grupo de determinado organismo fóssil está extinto.

A Paleontologia, como ciência natural e histórica, está permeada de conceitos, inferências e interpretações referentes a eventos geológicos, geográficos e evolutivos do mundo vivo que se enquadram numa história de escala de bilhões de anos. A difusão do conhecimento paleontológico torna-se importante, uma vez que auxilia no entendimento de processos naturais e de eventos globais de nosso planeta (Schwanke e Silva 2004).

O tema Paleontologia está inserido no currículo escolar como parte integrante do bloco de conteúdo intitulado "A natureza cíclica da Natureza", que por sua vez faz parte do tema transversal "Meio Ambiente". Os temas transversais não são tratados como novos conteúdos que somente são acrescentados aos já existentes, mas são incorporados a fim de desenvolver a capacidade de pensar e de compreender, bem como interagir adequadamente com o mundo que nos rodeia (Brasil 1998).

Apesar dos currículos do Ensino Básico, particularmente do Ensino Fundamental, apresentarem-se cada vez mais flexíveis possibilitando aos professores um ensino mais dinâmico, interativo e estimulante através da abordagem de temas transversais, Marques (1999) ressalva que conteúdos sobre Paleontologia ainda se mantêm distantes da sala de aula.

Por outro lado, Schwanke e Silva (2004) ressaltam que em instituições de pesquisa e de ensino superior verificam-se os primeiros processos de geração e disseminação de conhecimentos sobre Paleontologia, visto que tudo que é produzido a partir de pesquisadores e professores é repassado para os alunos de graduação ou de pós-graduação. Portanto, estas instituições também podem contribuir para a difusão da Paleontologia, oportunizando à comunidade um maior contato com o conhecimento sobre o estudo dos fósseis a partir de práticas não-formais de ensino.

Vale ressaltar que atividades não-formais de ensino constituem momentos de intensa relação social, uma vez que complementam a escola contribuindo para uma melhor apreensão dos conteúdos trabalhados, motivando cada vez mais os professores a explorarem os diversos temas abordados nos espaços extraescolares também na sala de aula (Valente et al. 2005).

$\mathrm{Na}$ última década, com a expansão de projetos de Extensão Universitária em âmbito nacional, houve uma tentativa de aproximação efetiva entre o universo acadêmico e o cotidiano da comunidade em geral. No que tange à Paleontologia, estes programas de ensino extensivo, ao utilizarem meios educativos como cursos, exposições, palestras e organização de eventos, contribuem significativamente para a presença mais marcante desta ciência nos âmbitos escolares e sociais.

Levando em consideração Nicholson (2002), é preciso refletir sobre o caráter científico das exposições, uma vez que estas não podem ser consideradas como meras coleções de objetos e exemplares que somente servem para ensinar determinados conteúdos. Desta forma, é necessário que as informações transmitidas em uma exposição possam contribuir para a formação de cidadãos capazes de interpretar, de forma mais ampla, os fenômenos sociais.

\section{Materiais e Métodos}

O presente trabalho foi realizado no segundo semestre de 2008 com alunos do $7^{\circ}$ ano ( $6^{\text {a }}$ série) do Ensino Fundamental de seis escolas da Rede Pública Municipal de Ensino de Aracaju, Sergipe. As 
escolas foram: E.M.E.F Anísio Teixeira; E.M.E.F Juscelino Kubitschek; E.M.E.F Olga Benário, E.M.E.F Presidente Vargas, E.M.E.F Santa Rita de Cássia e E.M.E.F Sérgio Francisco. .

\section{Diagnóstico da Exposição e atividades desenvolvidas}

A exposição de fósseis do Laboratório de Paleontologia da UFS é composta por exemplares de invertebrados marinhos, como amonóides, bivalves, gastrópodes, equinóides, tubos de crustáceos e de poliquetas, além de restos de vertebrados marinhos como vértebras de peixes e dentes de tubarão. Estes fósseis são encontrados em formações geológicas da fase marinha da Bacia de Sergipe, denominadas Formação Riachuelo, Formação Cotinguiba e Formação Calumbi, que representam os eventos de transgressão marinha na bacia de Sergipe e são importantes para o entendimento da origem e evolução do Oceano Atlântico.

Estão, também, expostos os restos de mamíferos gigantes datados do Pleistoceno que compreendem partes do esqueleto da preguiça gigante, toxodon e mastodonte. Lenhos fossilizados e fósseis de corais do período Cretáceo, além das ferramentas empregadas pelo paleontólogo, tanto na coleta, quanto na preparação dos exemplares catalogados, completam a exposição do Laboratório.

Nas paredes do laboratório são expostos painéis que ilustram o tempo geológico e as etapas da separação das placas sul-americana e africana e a consequente origem do Oceano Atlântico, bem como mapas que evidenciam quais municípios do Estado de Sergipe foram cobertos pelo mar do Cretáceo, e quadros ilustrativos com mamíferos pré-históricos.

Inicialmente, alunos e professores foram recebidos em sala de aula onde foram transmitidas e discutidas informações básicas sobre Paleontologia, como:

i) O que é Paleontologia?

ii) O que são fósseis?

iii) Qual a importância dos fósseis para compreender os ambientes pretéritos e a evolução dos seres vivos?

iv) Como se dá o processo de fossilização?

v) Quais são os principais fósseis encontrados em Sergipe?

\section{Confecção de textos pelos alunos}

No intuito de analisar os conhecimentos dos alunos sobre Paleontologia e também com a

1 Escola Municipal de Ensino Fundamental intenção de compreender como estes perceberam todo o processo de visitação, ao final de cada visita, foi solicitado que escrevessem um texto. Este deveria ser uma explanação que abordasse as mais variadas impressões individuais sobre a atividade desenvolvida.

Utilizando-se da pesquisa qualitativa, foram analisados 164 textos, nos quais se buscou elementos que enfatizassem quatro temas: "Conhecimento sobre Paleontologia"; "O que mais chamou atenção durante a visita"; "Recepção e explicação dos monitores"; e "Opinião sobre as atividades extraescolares". Com os dados obtidos, foram formuladas categorias que reunissem respostas com significados e sentidos comuns, como mostram as Tabelas I, II, III e IV.

Segundo Oliveira (2005), o uso de categorias consiste em agrupar criteriosamente informações com características comuns, permitindo a compreensão das informações de forma sistematizada e coerente, visto que a combinação de técnicas qualitativas e quantitativas possibilita a obtenção de dados mais completos, ricos e reais sobre o objeto estudado.

\section{Entrevistas com os professores}

Foram realizadas entrevistas com os professores responsáveis por cada turma, a fim de verificar quais as concepções dos docentes em relação à contribuição das práticas não-formais de ensino realizadas no laboratório de Paleontologia para o processo de aprendizagem dos seus alunos, bem como o envolvimento e a motivação dos mesmos durante a visita.

As entrevistas foram compostas por quatro questões abertas que, conforme Flick (2004) permitem sugestões para explanação do conhecimento implícito. As questões foram: i) Os alunos se interessam por atividades extraescolares? ii) Como você avalia o desempenho dos alunos durante a realização da exposição? iii) O que a visita acrescentou para os alunos?

\section{Resultados e Discussão}

\section{Análise dos textos confeccionados pelos alunos}

As informações básicas referentes ao tema "Conhecimento sobre Paleontologia" apreendidas pelos alunos durante a exposição foram agrupadas em categorias que estão presentes na Tabela I. É 
possível notar que os conceitos de Paleontologia e de Fósseis foram bem lembrados e citados pelos estudantes, o que implica em afirmar que a discussão destes temas caracterizou-se como bastante significativa para o entendimento de toda explicação sobre os fósseis de Sergipe.

Estão presentes nos textos dos alunos trechos que revelam a importância da Paleontologia. Um aluno expressou que "a importância da Paleontologia é que nós através dos fósseis descobrimos como surgiram os primeiros seres vivos da Terra e o seu objetivo éde descobrir cada vez mais fósseis para descobrir as vidas que já existiram".

A Tabela II está relacionada com a visita guiada pelos monitores. Muitos alunos se impressionaram com a maioria dos fósseis expostos, tanto com os exemplares de animais marinhos do Cretáceo quanto com os restos de mamíferos gigantes do Pleistoceno, além de acharem interessante a Linha do Tempo como recurso didático.

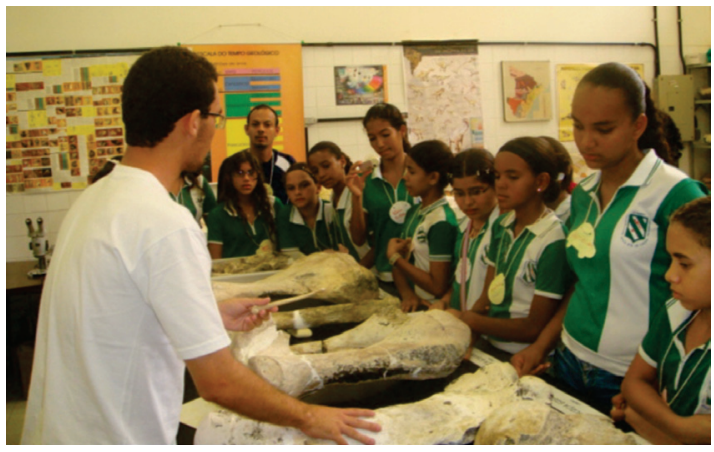

Figura 1. Visita dos alunos da E.M.E.F. Presidente Vargas à exposição de fósseis do Laboratório de Paleontologia da UFS

A disposição dos fósseis dentro de uma sequência cronológica do registro geológico (Fig. 1) associadas às informações transmitidas pelos monitores favoreceu o entusiasmo e a curiosidade dos alunos pelo material exposto.

Tabela I: Categorias para o tema Conhecimento sobre Paleontologia

\begin{tabular}{l|l}
\hline Ciência que estuda a vida pretérita por intermédio dos fósseis & $38 \%$ \\
\hline Fósseis são restos e vestígios de seres antigos & $20 \%$ \\
\hline Não citaram o tema & $19 \%$ \\
\hline A Terra tem 4,5 bilhões de anos & $14 \%$ \\
\hline Os seres vivos evoluem ao longo do tempo geológico & $9 \%$ \\
\hline
\end{tabular}

Tabela II: Categorias para o tema $\mathrm{O}$ que mais chamou atenção durante a visita

\begin{tabular}{l|l}
\hline Fósseis da Preguiça-gigante & $27 \%$ \\
\hline Fósseis de animais marinhos & $25 \%$ \\
\hline Linha do tempo & $21 \%$ \\
\hline Não citaram o tema & $15 \%$ \\
\hline Explicação dos monitores & $12 \%$ \\
\hline
\end{tabular}

Tabela III: Categorias para o tema Avaliação da recepção e explicação dos monitores

\begin{tabular}{l|c}
\hline Os monitores explicam bem & $40 \%$ \\
\hline Não citaram o tema & $22 \%$ \\
\hline A recepção foi muito boa & $19 \%$ \\
\hline Aprendi muito com a visita & $10 \%$ \\
\hline Os monitores foram atenciosos & $9 \%$ \\
\hline
\end{tabular}

Tabela IV: Categorias para o tema Opinião sobre as atividades extraescolares

\begin{tabular}{l|l}
\hline Oportunidade para aprender coisas novas & $32 \%$ \\
\hline Não citaram o tema & $26 \%$ \\
\hline Que tivessem mais vezes & $18 \%$ \\
\hline Importante incentivo para aprender & $13 \%$ \\
\hline Nova experiência para aprender & $11 \%$ \\
\hline
\end{tabular}

Apoiando-se em Clarck (2002), exposições de coleções científicas constituem-se em meios de comunicação entre instituições de ensino e a comunidade que as visita, sendo que a comunicação caracteriza-se como propícia quando há uma compreensão adequada por parte dos receptores. Portanto, para que tais instituições se mostrem como eficazes centros de educação, há necessidade tanto do domínio do conhecimento sobre o acervo quanto da habilidade de se comunicar por parte dos responsáveis pela divulgação, estimulando os visitantes a se concentrarem no assunto e perceberem a importância do mesmo.

A relação sujeito-objeto, entendida como ação dinâmica, foi mediada pelos monitores de modo que esta interação estimulasse o aprendizado por meio de ques- 


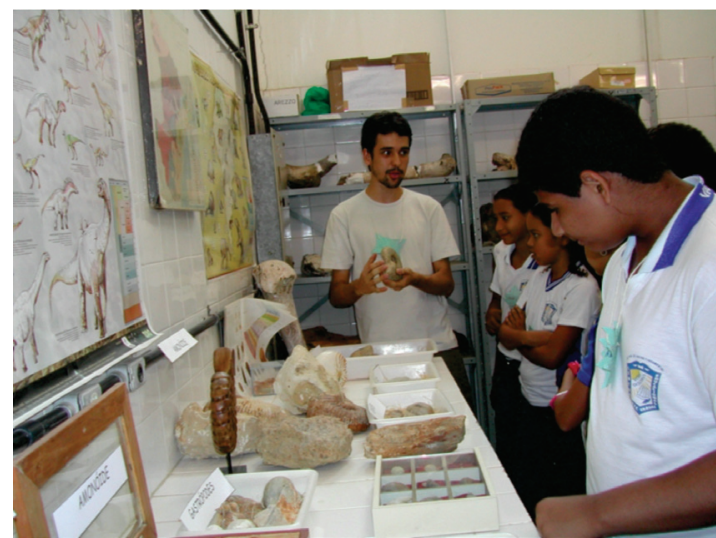

Figura 2. Visita dos alunos da E.M.E.F. Santa Rita de Cássia à exposição de fósseis do Laboratório de Paleontologia da UFS

tionamentos. Com a abordagem prévia dos conhecimentos introdutórios de Paleontologia, procurou-se possibilitar o engajamento intelectual dos estudantes. Sendo assim, baseando-se na Tabela III, é possível verificar que a apresentação e explicação fornecidas pelos monitores contribuíram para a apreensão das informações transmitidas, uma vez que a atuação dos monitores e a interação destes com o público foram correspondidas positivamente.

A forma como se procedeu a comunicação e a interação dos monitores com o público-alvo (Fig. 2) está presente em alguns trechos como: "eu acho que a recepção foi ótima. Os monitores foram muito simpáticos, comunicativos e divertidos" e "os monitores foram super legais conosco, e nós aprendemos mais com as explicações deles".

Além disso, o papel dos monitores é fundamental não somente como orientador, mas também como organizador da visita na tentativa de impedir que ocorra alguma dispersão dos alunos que acabe por atrapalhar a exploração proveitosa das exposições. Ao contrário do que se possa imaginar não se deseja, no entanto, um aluno que tenha seu comportamento moldado pela disciplina escolar, ou seja, bem comportados, em silêncio e não questionadores. Segundo Marandino (2001), é importante a liberdade e a autonomia dos alunos na exploração dos espaços da exposição, incentivando uma forma de interação com o conhecimento diferenciado da escola.

Com a Tabela IV, nota-se que muitos alunos se interessam por atividades conduzidas fora da sala de aula, por se sentirem estimulados diante de lugares, atividades e informações diferentes da realidade e do cotidiano da escola onde estudam.
Um aluno escreveu que "a escola deveria fazer outras visitas, porque ficar só na escola o aluno fica enjoado e com isso não se incentiva a estudar, pois muitas das vezes aprendemos mais fora da escola". Outro estudante citou: "eu acho que estas atividades fora da escola ajudam muito a nós alunos, para o nosso desenvolvimento e no nosso estudo também".

Foi possível perceber que a exposição constitui-se em um importante recurso para a inserção dos conhecimentos sobre Paleontologia na educação básica, além de ter estimulado os alunos a aprender sobre os fósseis.

Reforçando, Zucon e colaboradores (2009) relatam que uma exposição de fósseis proporciona comunicação entre as comunidades atendidas e a Universidade, possibilitando a esta última cumprir seu papel social de divulgar os conhecimentos construídos no meio acadêmico e de intervir de forma comprometida na sociedade, promovendo a inclusão desta por meio da interdisciplinaridade do Ensino de Paleontologia.

\section{Análise das entrevistas com os professores}

\section{Concepções dos docentes quanto à atuação e nível de aprendizagem dos alunos durante a visita}

Por intermédio das entrevistas realizadas com os professores que acompanharam cada turma, foi possível identificar o interesse dos alunos em atividades extraescolares, neste caso, a exposição de fósseis no Laboratório de Paleontologia da UFS.

De forma unânime, os professores afirmaram que seus alunos se interessam e sempre requisitam oportunidades para conhecer outros lugares. Uma professora relatou que "isso aí é o que eles mais cobram, sair da escola (...) e é uma cobrança maior, todos querem sair, todos querem". Outro professor afirma que "eles me surpreenderam (...) nem na sala de aula perguntam deste jeito."

Outro professor mencionou que gostou da desenvoltura dos seus alunos, visto que mostraram interesse, ressaltando que na sala de aula, devido à maneira de abordagem dos conteúdos, os estudantes não atuam de forma motivadora, mas diante de recursos, objetos e informações novas, eles se revelam bastante atentos e participativos.

Estes fatos fazem crer que a experiência da visita ao laboratório de Paleontologia, sob o ponto de vista da aprendizagem, pode abrir espaço para a participação de alunos que não costumam se manifestar na sala de aula. 
Os docentes argumentaram que atividades desenvolvidas fora da escola estimulam a aprendizagem dos alunos e aguçam suas curiosidades. Tal asserção é percebida na passagem de uma professora: "eu acredito que desta forma eles passam a conhecer melhor o mundo que existe lá fora. Com isso eles podem ter mais vontade de querer aprender". Outro professor ainda destacou que "além da aprendizagem adquirida, eu acho que vislumbra a possibilidade de um futuro". Tal apontamento pode ser confirmado por meio da explanação de um aluno: "eu gostei muito da visita à UFS. Tomara que daqui a alguns anos eu esteja estudando lá, será uma grande oportunidade".

Conforme Zucon e Silva (2010), visualizar e ter contato direto com os fósseis proporciona aos estudantes o desenvolvimento da capacidade de formação de imagens que são fundamentais no processo de ensino e aprendizagem para o aluno do sétimo ano. Então, as exposições de fósseis, ao integrar o conhecimento teórico com práticas pedagógicas, atuam como uma relevante estratégia educacional. Sobre esta questão, um professor relata "(...) uma coisa é você falar sobre o fóssil e outra coisa é você visualizar. Isso estimula o aluno".

Percebe-se, desta forma, a importância de unir a teoria com a prática, uma vez que, segundo os docentes, os estudantes não aprenderiam satisfatoriamente os conteúdos sobre Paleontologia somente na sala de aula. Os professores destacaram, ainda, que a visita à exposição acrescentou para seus alunos muito conhecimento sobre o estudo dos fósseis.

O interesse dos professores em visitar os espaços extraescolares tem, portanto, relação direta com o programa de ciências que desenvolvem. Comumente, o professor do Ensino Fundamental e Médio que procura estes espaços está interessado em conteúdos diretamente relacionados com a matéria que ele está dando em aula. Este tipo de anseio se justifica, pois segundo Marandino (2001) uma visita extraescolar deve apresentar algum vínculo com o que está sendo desenvolvido em sala de aula.

É sabido que a abordagem dos conteúdos de Paleontologia tem se mantido bem distante das salas de aula, devido a fatores como: a discrepância entre a linguagem científica e linguagem cotidiana dos alunos; a falta de conexão entre o currículo escolar e as experiências vividas pelos alunos; a deficiência dos livros didáticos dirigidos ao Ensino Fundamental. Nestes há geralmente negligência abordagem inadequada de temas relevantes para a compreensão desta ciência como a definição de fóssil, origem da vida, eras geológicas e evolução, assim como a não atualização dos professores em relação aos conhecimentos científicos emergentes (Schwanke e Silva 2004, Moraes et al. 2007, Sobral et al. 2007).

A asserção acima pode ser confirmada por um professor que argumenta: "nós professores, inclusive, trabalhamos com dificuldades sobre os assuntos de Paleontologia dentro da sala de aula, até porque os livros didáticos falam muito pouco. Então, para eles, foi uma coisa nova que a gente fala pouco e eles puderam ver na realidade. Foi bom!"

Nesse ponto, é interessante destacar três aspectos importantes que constituem o pilar ensino-aprendizagem e que estão relacionados entre si:

É evidente que o livro didático ainda continua sendo o recurso mais utilizado pelos professores na busca de conhecimento. O professor organiza, desenvolve e avalia seu trabalho pedagógico de sala de aula. Por isso, a importância da escolha de um bom livro didático (Vieira et al. 2009);

Os docentes não devem elaborar suas aulas seguindo, somente, o livro didático, mas pesquisando vários livros, artigos científicos, atualizando-se por meio de cursos e congressos. Desta forma, além de uma constante atualização do conhecimento teórico, o docente deve tornar mais dinâmico e atraente o aprendizado dessa ciência, permitindo uma melhor observação de um grande conjunto de informações, auxiliando o processo de ensino-aprendizagem (Reis et al. 2005);

Um dos fatores que influi negativamente no processo de aprendizagem é a preparação inadequada dos educadores. As deficiências consistem na falta ou na má formação que resultam na desqualificação do profissional. Tais situações acabam por determinar a má qualidade do ensino (Krasilchik 1986).

\section{Considerações Finais}

Por meio da análise qualitativa dos textos e entrevistas, é possível apontar que a exposição de fósseis do Laboratório de Paleontologia da Universidade Federal de Sergipe, como um espaço não-formal de ensino, é capaz de promover difusão satisfatória dos conhecimentos paleontológicos para a comunidade estudantil, atuando de forma a complementar o ensino formal, além de reduzir o déficit da abordagem de temas sobre o estudo dos fósseis nas salas de aula.

A exposição de fósseis de Sergipe é atividade extraescolar que possibilitou maior interação entre 
os responsáveis pelas atividades e os estudantes da rede pública municipal de ensino de Aracaju. Tal interação ofereceu aos alunos oportunidades de aprender, de maneira estimulante e interativa, conhecimentos sobre os fósseis e sua importância.

Instituições extraescolares como o laboratório de Paleontologia e as escolas são espaços sociais que possuem histórias, linguagens, propostas educativas e pedagógicas distintas. Socialmente são espaços que se interpenetram e se complementam mutuamente e ambos são imprescindíveis para formação do cidadão cientificamente alfabetizado.

\section{Referências Bibliográficas}

Afonso A.J. 2001. Os Lugares da Educação. In: Von Simon O.R.M., Park M.B., Fernandes R.S. eds. 2001. Educação não-formal: cenários da criação. Campinas: Unicamp/Centro Memória. p. 29-36.

Brasil. Ministério da Educação. 1998. Parâmetros Curriculares Nacionais: terceiro e quarto ciclos: apresentação dos temas transversais. Secr. Educação Fundamental: MEC/SEF, Brasília. 436p.

Clarck G. 2002. As exposições vistas pelos olhos dos visitantes. A chave para o sucesso da comunicação em museus. In: Semin. Intern. Implant. Centros e Museus de Ciência, Rio de Janeiro, 2002. Anais... Rio de Janeiro: Uinv. ed. do io de aneiroFRJ.

Flick U. 2004. Uma introdução à pesquisa qualitativa. Porto Alegre: Bookman. 312p.

Krasilchick M., Marandino M. 2004. Ensino de Ciências e Cidadania. São Paulo: Moderna. 88p.

Krasilchik M. 1986. O Professor e o Currículo das Ciências. São Paulo: EPU. 80p.

Marandino M. 2001. Interfaces na relação museu-escola. Cad. Catar. Ensino em Física. 18(1):85-100.

Marques R. B. 1999. A Paleontologia no Ensino Fundamental. In: Congr. Bras. Paleont., 16, 1999. B. Res... Crato: Univ. Regional do Cariri, SBP.

Moraes S.S., Santos J.F.S., Brito M.M.M. 2007. Importância dada à Paleontologia na educação brasileira: uma análise dos PCN e dos livros didáticos utilizados nos colégios públicos de Salvador, Bahia. In: I.S. Carvalho ed. 2007. Paleontologia: cenários da vida. Rio de Janeiro: Interciência. v. 2, p. 71-75.

Moreira I.C. 2006. A inclusão social e a popularização da ciência e tecnologia no Brasil. Inclusão Social, 1(2):11-16.

Nicholson F. 2002. Museologia aplicada ao desenvolvimento de exposições no século XXI. In: Seminário Internacional de Implantações de Centros e Museus de Ciência, Rio de Janeiro, 2002. Anais... Rio de Janeiro: UFRJ.

Oliveira M.M. 2005. Como fazer pesquisa qualitativa. Recife: Bagaço. 191p.

Reis M.A.F., Carvalho C.V., Carvalho J.V., Rodrigues M.A., Medeiros M.A.M., Villena H.H., Oliveira F.M., Dornelas V.R. 2005. Sistema multimídia educacional para o Ensino de Geociências: uma estratégia atual para a divulgação da Paleontologia no Ensino Fundamental e Médio. Anuário Inst. Geoc., 28(1):70-79.

Schwanke C., Silva M.A.J. 2004. Educação e Paleontologia. In: I.S. Carvalho ed. 2007. Paleontologia: cenários da vida. Rio de Janeiro: Interciência. v. 2, p. 123-130.

Sobral A.C.S., Zucon M.H., Machado S.R.G. 2007. Jogos educativos para o Ensino de Paleontologia na educação básica. In: I.S. Carvalho ed. 2007. Paleontologia: cenários da vida. Rio de Janeiro: Interciência. v. 2, p. 13-21.

Valente M.E., Cazelli S., Alves F. 2005. Museus, ciência e educação: novos desafios. Rio de Janeiro: História, Ciências, Saúde, 12:183-203.

Vieira F.S., Matias A.B., Zucon M.H., Carriço J.M. 2009. Avaliação do ensino de educação ambiental a partir da percepção dos professores do município de Aracaju, Sergipe. Scientia plena, 5(8):1-5.

Vieira F.S., Zucon M.H., Santana W.S. 2010. Análise dos conteúdos de paleontologia nos livros didáticos de biologia e nas provas de vestibular da UFS e do ENEM. In: EDUCON Colóq. Intern. Educação e Contemporaneidade, 4, 2010. Anais... São Cristóvão: Univ. Fed. de Sergipe.

Zucon M.H., Reis V.S., Souza J.F., Almeida L.F. 2009. Ensino de Paleontologia: Diferentes Perspectivas para o Ensino Fundamental. In: EDAPECI Semin. Educação, Comunicação, Inclusão e Interculturalidade, 2, 2009. Anais... São Cristóvão: Univ. Fed. de Sergipe.

Zucon M.H., Silva M.A. 2010. Violência Cultural e os Conhecimentos Paleontológicos de Sergipe. In: Jalali V.R.R. 2010. Estudos para a Paz. Aracaju: Criação. p.283-300. 